\title{
Research on the Improvement of Scallop Breeding Industry in Shandong Province based on the Stackelberg Model
}

\author{
Xiaochun Xu \\ Yantai Research Institute, Chinese Agriculture University, Yantai, China \\ 1583995019@qq.com
}

\begin{abstract}
Shandong is an important producing area of scallop in China, but its development has gradually entered the bottleneck period in recent years. According to the characteristics of scallop breeding industry, the Stackelberg expansion model is formed. After the model discussion, it is concluded that cost and knowledge spillover effect are two important factors affecting the income of scallop breeding industry. To a certain extent, industrial agglomeration is conducive to the reduction of costs and the production of knowledge spillover effects. It is necessary to improve the current situation of scallop bottle neck in Shandong Province with the help of cluster effects and promote the establishment of fishery professional cooperatives, guiding the healthy development of scallop breeding industry.
\end{abstract}

Keywords: Scallop Culture; Stackelberg Model; Industrial Cluster.

\section{Introduction}

Scallop is one of the important varieties of aquaculture in our country. In 2018, the production of Scallop mariculture in Shandong Province was ranked first in the country. As an important producing area of Scallop in China, the area of Scallop culture has been expanding in recent years. However, in the context of over breeding, the marine ecological damage caused by the decline of marine fertility, serious seawater pollution and climate change and the high risk of aquaculture industry have slowed down the developing speed of Shandong scallop industry. As shown in Figure 1, the scallop producer price index shows an inverted " $U$ " type, which shows a downward trend in recent years and indirectly indicates that the market demand of scallop has been reduced. while at the same time, the area of scallop culture as a whole shows an expanding trend. Scallop belongs to the category of agricultural products and its demand is inelastic, in which case the market slightly oversupply is likely to cause a sharp fall in prices and then easy to cause scallop farmers to shrink income. At present, some of the reasons are that the entry barriers of scallop breeding industry are unreasonable, which makes the density of aquaculture farmer too large, exceeding the double load of market demand and marine ecology, making Shandong scallop breeding industry enter the bottleneck period under the passage of time.

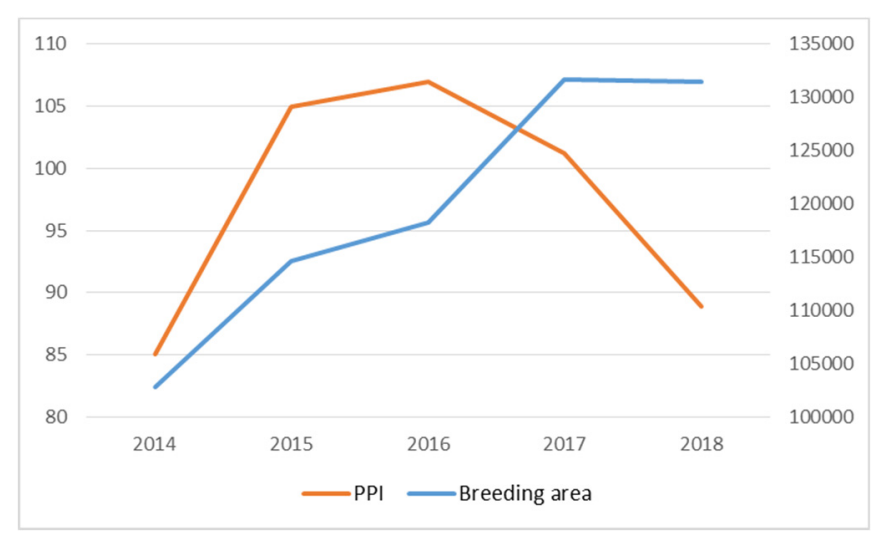

Fig 1. Composite chart of PPI and breeding area of Scallop in 2014-2018

Source: China Agricultural Price Survey Yearbook, China Agricultural Statistics Yearbook, China Fisheries Statistics Yearbook 2019 
The Stackelberg model is suitable for analyzing the market competition based on the change of output, which accords with the characteristics of the internal market competition of Shandong scallop breeding industry. Based on the Stackelberg model, this paper hopes to analyze the internal competition mechanism of scallop breeding industry. Then using the industrial cluster effect (Rugman thinks that industrial cluster is an organization formed by multiple enterprises with the same nature because of complementary or competitive relationship in production chain) to prove up the bottleneck restricting the sustainable development of scallop breeding industry in Shandong.

\section{Establishment of Stackelberg Development Model of Scallop Breeding Industry}

The difference of enterprise size is an important factor affecting the formation of market equilibrium point under gaming behavior. In scallop breeding industry, there is market competition between large breeding enterprises and small breeding enterprises. Because of the difference of enterprise scale, a state of asymmetric game is naturally formed. Large aquaculture enterprises play a more "leader" role and have more initiative in production decision-making. It has considerable investment funds, information sources, sales channels, breeding experience and other advantages, whether in the face of uncertain cost changes or due to natural disasters such as weather sudden business risks, can quickly respond to the existing situation to make a relatively optimal output choice. In addition, when the market demand is strong, it can increase the number of employed workers, expand the area of leased sea area, and appropriately increase the purchase quantity of shellfish seedlings, to adjust the output according to the market demand and its own load capacity. When the scallop culture industry falls into the bottleneck period, it can take the lead to detect and actively improve the yield and quality of its own culture by using technical means, open the market to actively create and find demand, and pass the bottleneck period by directly or indirectly adjusting the output. Small farming enterprises play a more "follower" role, which is limited by their own size, difficult to have a series of advantages in the market competition, in the production selection is relatively passive position. The two show the state of master-slave game, so this paper uses Starkberg development model to explore the market competition between different scale scallop farming enterprises, and the industrial cluster effect is further analyzed.

\subsection{Stakelberg Extended Model Hypothesis}

Hypothesis 1: master-slave game. There are only large-scale aquaculture enterprises A and smallscale aquaculture enterprises B in market, and small-scale aquaculture enterprises B make their own yield decisions according to the output choices A by large-scale aquaculture enterprises. The position of the two in the market competition and the order of decision-making show differences.

Hypothesis 2: yield competition. Because the selling price of scallop in the market varies according to the market demand, the seller, the selling time and so on, under normal circumstances, it is difficult for large aquaculture enterprises and small aquaculture enterprises to intervene too much in the market price of scallop, and they participate in the market competition more by the way of output selection.

Hypothesis 3: cost assumption. Cost of scallop culture includes fixed cost and variable cost. (1) fixed cost assumption F. Barriers to entry are included in fixed costs in the form of sunk costs, which also include depreciation of equipment and water rent. It is assumed here that large and small scallop farming enterprises need to bear the same fixed cost (2) variable cost assumption. The variable cost is approximately equal to the product of marginal cost $\mathrm{V}$ and output $\mathrm{Y}$, including seedling cost, material cost and labor cost.

Hypothesis 4: knowledge spillover effect hypothesis. Knowledge spillover is the process of oneway penetration of knowledge and information between the producer enterprise and other enterprises without this kind of knowledge in order to promote the technological innovation of the inferior technology enterprises. Because knowledge spillover often occurs between subjects with close spatial 
distance, it has certain geographical dependence. Industrial clusters provide conditions for knowledge spillover, which has significant externalities and plays an important role in the improvement of enterprise profits. large-scale aquaculture enterprises create a good environment for their internal knowledge flow and innovation, and there is a greater possibility of knowledge spillover effect $(\mathrm{L}>=0)$; however, the possibility of knowledge spillover effect within small enterprises is almost zero because of the limitation of personnel, division of labor, scope and other conditions.

In this paper, the traditional Stackelberg model is expanded to change the assumption that the marginal cost of the enterprise in the original model is 0 , and it is combined with the cost characteristics of the scallop breeding industry to form a more suitable for scallop breeding industry.

\subsection{Stakelberg Development Model}

Using this model, it is necessary to observe how the price changes with the output, so it is assumed that the $\mathrm{Y}_{\mathrm{a}}$ is a large scallop breeding enterprise, the $\mathrm{Y}_{\mathrm{b}}$ is a small scallop breeding enterprise, and the $\mathrm{P}$ is the market price of scallop. Then the reverse demand function of scallop breeding market is

$$
P=a-b\left(Y_{a}+Y_{b}\right), a, b>0
$$

Profit for small scallop enterprises is

$$
\begin{aligned}
\pi_{b} & =P Y_{b}-V_{b} Y_{b}-F \\
& =a Y_{b}-b Y_{b} Y_{a}-b Y_{b}^{2}-V_{b} Y_{b}-F
\end{aligned}
$$

Its profit maximization condition is

$$
\frac{\partial \pi_{b}}{\partial Y_{b}}=a-b Y_{a}-2 b Y_{b}-V_{b}=0
$$

Therefore, it can be concluded that small-scale aquaculture enterprises B make their own output choices according to the A output of large-scale aquaculture enterprises

$$
\mathrm{Y}_{\mathrm{b}}=\frac{1}{2 \mathrm{~b}}\left(\mathrm{a}-\mathrm{V}_{\mathrm{b}}-\mathrm{bY}\right)
$$

Therefore, the profits of small farming enterprises are

$$
\pi_{\mathrm{b}}=\frac{1}{4 \mathrm{~b}}\left(\mathrm{a}-\mathrm{V}_{\mathrm{b}}+\mathrm{bY} \mathrm{a}^{2}-\mathrm{F}\right.
$$

Because of the possibility of knowledge spillover effect in large scallop breeding enterprises, the profit formula A large scallop enterprises can be constructed and the input formula (5) can be obtained

$$
\pi_{a}=-\frac{\mathrm{b}}{2} Y_{a}^{2}-V_{a} Y_{a}+\frac{a+V_{b}}{2} Y_{a}-F+L
$$

Its profit maximization condition is

$$
\frac{\partial \pi_{a}}{\partial Y_{a}}=-b Y_{\mathrm{a}}+\frac{a+V_{b}}{2}-V_{\mathrm{a}}=0
$$

According to this, it can be concluded that the optimal output choice A large-scale aquaculture enterprises is 
Volume 15 (2021)

$$
Y_{\mathrm{a}}=\frac{1}{2 \mathrm{~b}}\left(a+V_{b}-2 V_{a}\right)
$$

As a result, the A profits of large aquaculture enterprises are

$$
\pi_{a}=\frac{1}{8 b}\left(a+V_{b}-2 V_{a}\right)^{2}-F+L
$$

Substituting the equation (8) into the equation (5), The profit of small farming enterprises:

$$
\pi_{\mathrm{b}}=\frac{1}{16 b}\left(-3 a+V_{b}+2 V_{a}\right)^{2}-F
$$

\subsection{Discussion on Model Results}

According to the Stackelberg expansion model, the optimal profit of small scallop breeding enterprises is obtained under the condition of making yield decision according to the yield selection of large scallop breeding enterprises.

(1) Directly from the results, $\pi_{a}>\pi_{b}$. Compared with small-scale aquaculture enterprises, the cost of labor and information is relatively small, which makes the cost of unit products decrease, and the internal scale economy is realized. At the same time, the occurrence of knowledge spillover effect makes it show obvious advantages in profit. And small farming enterprises want to increase profits, need to use cluster effect. Industrial clusters provide a good budding environment for economies of scale. The speed of information, resources and technology circulating among different subjects is accelerated, which makes the overall efficiency improve and forms the scale benefit, to improve the profit of the enterprise.

(2) Discuss and interpret the above model from a fixed cost perspective

(1) $F \geq \frac{1}{8 b}\left(a+V_{b}-2 V_{a}\right)^{2}+L$, Both large-scale aquaculture enterprises and small-scale aquaculture enterprises are in a state of negative profit under the optimal high F will hinder the entry of enterprises, and too high sunk cost rate will cause enterprises in the industry to withdraw because of insolvency. It is not conducive to industrial cluster effect.

(2) $F \leq \frac{1}{16 \mathrm{~b}}\left(-3 a+V_{b}+2 V_{a}\right)^{2}$, At the same time, low entry barriers make farmers neglect the concept of environmental protection, safety and science, and excessive marine grazing causes marine pollution caused by oil leakage, excessive scallop feces and the decline of mariculture fertility, which further affects the actual income and makes it difficult to realize the long and healthy development of scallop breeding industry.

(3) $\frac{1}{16 b}\left(-3 a+V_{b}+2 V_{a}\right)^{2}<F<\frac{1}{8 b}\left(a+V_{b}-2 V_{a}\right)^{2}+L$, Large-scale aquaculture enterprises have been in a state of positive profit, while small-scale aquaculture enterprises are not profitable, there will be two situations: first, a large number of small-scale enterprises withdraw from the scallop culture market, although the concentration of enterprises in the market is obviously improved, but it is easy to form a monopoly situation, which is not conducive to enhancing the vitality of scallop culture market.

\section{Countermeasures and Suggestions}

It can be concluded from the model that cost and knowledge spillover effect are two important factors affecting the income of scallop breeding industry, and industrial cluster is beneficial to the reduction of cost and the production of knowledge spillover effect to a certain extent. In the actual 
operation process, individual farmers have a strong sense of powerlessness, whether it is the breeding cost beyond their personal burden level, the limited local market, the unsatisfactory income, or the idea of restoring marine ecology. Individual farmers in the market difficulties and self-financing conditions, in the face of scallop breeding bottleneck period, lack of adequate coping ability. Combined with the current situation of scallop culture bottleneck period in Shandong Province, it is necessary to improve the condition of large number and scattered distribution of scallop culture main body and oversupply of scallop market with the help of cluster effect, to promote the establishment of fishery professional cooperative. Guide the healthy development of scallop culture industry.

From the point of view of government regulation, the fixed cost of scallop breeding industry includes sunk cost, sea area rent and depreciation of equipment. Depreciation is not considered because it is difficult to control artificially. In view of the sunk cost of the barrier of entry, the government needs to strengthen its own sense of responsibility, control the barrier of entry within a reasonable range, strengthen the use of big data and timely control it in combination with the new mode of "Internet ". In view of the sea area rent, the government can provide the policy preferential treatment and the subsidy appropriately for the large and cooperative scallop culture main body, such as reducing the sea area rent appropriately, providing the tax preferential treatment and so on, using the policy guidance, guides the scallop culture industry concentration degree to increase, creates the positive policy environment for the cluster effect.

From the point of view of producer management, we should develop large-scale and intensive management of scallop culture, build marine pastures, and construct fishermen's professional cooperatives of Strengthen the interest connection between cooperatives, guide farmers to actively invest in cooperatives with labor, capital, technology and other factors of production, realize the extension of industrial chain in the region, improve the effective utilization rate of production factors, facilitate the germination of knowledge spillover effect, and realize the benign development of scallop culture technology and management experience. Through cluster effect, it is not only beneficial to realize scale economy, reduce marginal cost, improve the ability of scallop breeding enterprises to deal with cost change, and further reduce the volatility and risk of scallop breeding industry. Extensive individual scallop breeding subjects without market competitive advantage consider withdrawing and further balance the supply and demand of scallop breeding market. Fishermen's specialized cooperative has the superiority which individual breeders cannot compare, its development concrete performance and the anticipated effect are as follows:

Under the professional cooperative mode of fishermen, the efficiency and efficiency of scallop culture are improved through specialized, standardized and mechanized production; the reasonable and diversified culture structure of scallop varieties is formed, and the risk is dispersed by combination, and the new varieties are introduced and improved to improve the quality and risk resistance of scallop fundamentally; To raise fishermen's awareness of the relationship between the restoration of marine ecology and their own income, to realize the marine ecological restoration project which is difficult to advance by individual farmers through fishermen's cooperatives, to carry out scientific and sustainable scallop breeding while protecting and producing, to reduce the loss of shellfish seedlings and to improve the quality of scallop breeding in a certain area, to realize "breeding processing and marketing" in a certain area, to effectively reduce logistics transportation and interpersonal costs, to extend the industrial chain and to realize the integration of production and marketing, and to optimize the profit structure; Under the management system with clear division of labor, a more accurate market analysis and sales combination scheme is formed, which is conducive to making a more flexible response strategy in the face of market supply and demand changes; under the support of sufficient funds and technical conditions, the inland market and international market are developed through cold chain technology and long-distance consignment, and the market scale is expanded to promote the balance between supply and demand and price recovery; and the negative impact of high operating risk of scallop breeding industry on individual income is effectively reduced under risk sharing, which is conducive to collective income increase. 


\section{References}

[1] Shang Q, Poon J P H, Yue Q. The role of regional knowledge spillovers on China's innovation[J] China Economic Review. 2012,23(04).

[2] Rugman A M, Verbeke A Transnational networks and global competition: An organizing framework [J] Research in Global Strategic Management.1995,5(1).

[3] Yu Jingkai, Gao Lei, Liu Shuguang. The analysis of port competition mechanism based on Stackelberg model --Taking port competition around Bohai Sea as an example, $[\mathrm{J}]$ Journal of Hebei University of Economics and Technology. 2008(06).

[4] Wang Bingwen, Li Wenxing. The study of game behavior and industrial concentration --coal enterprises [J] logistics technology based on Starkberg model. 2012(09).

[5] Ma Zongguo, Zhang Yongmei. A theoretical Review of Industrial clusters [J] Journal of Hubei Institute of Economics: humanities and Social Sciences Edition. 2006(01).

[6] Wang Ji-ci. Analysis of Enterprise proximity and agglomeration in Industrial Cluster and Industrial Park Development [J] Chinese soft Science. 2015(12).

[7] Xu Weixiang. A study on the interactive development mechanism and operation mode of industrial cluster and urbanization [M] Zhejiang University. 2005.

[8] Sun $\mathrm{Yu}, \mathrm{Mu}$ Yongtong, Xu Tao. Study on the cost benefit and value chain of fishery industry under the background of rural revitalization --Taking scallop industry in Shandong Province as an example, [J] agricultural resources and regionalization in China. 2019,40(04). 